\title{
Factors Influencing Innovation Adoption in a Higher Education Institution
}

\author{
Sanet Haupt* and Alex Antonites \\ University of Pretoria, South Africa
}

\begin{tabular}{|c|c|}
\hline ARTICLE INFO & ABSTRACT \\
\hline $\begin{array}{l}\text { Keywords: } \\
\text { Case Study } \\
\text { Qualitative } \\
\text { Innovation } \\
\text { Adoption } \\
\text { Higher Education }\end{array}$ & $\begin{array}{l}\text { Accelerated skills development and an unconditional pursuit to } \\
\text { enhance competencies on numerous levels are two key } \\
\text { physiognomies of the post-recession phase of } 2008 \text { in South Africa. } \\
\text { The research was informed by a contextual perspective, and relied on } \\
\text { interpretive, constructivist epistemology to reveal these phenomena. } \\
\text { The primary research question driving this qualitative study was to } \\
\text { analysis the concept of innovation adoption within a HE context, } \\
\text { factors impacting on the adoption process, and the relationships } \\
\text { between the identified phenomena, without explaining the reasons } \\
\text { behind these relationships. This study could serve to inform and } \\
\text { focus such policies and paradigms or direct further research. } \\
\text { Recognizing and rewarding innovation adoption in the institution } \\
\text { could be extended and enhanced. }\end{array}$ \\
\hline
\end{tabular}

\section{Introduction}

\subsection{SA's innovation potential and indicators}

Comparing the competitive position of countries on a global scale, as described in the GCR (2010-2011), is a measure to identify distinguishing indicators that influence the productive potential of counties, which can be acted upon to advance their economic competitiveness. The top ten countries in the G2 for 2012-2013 were: Switzerland, Singapore, Finland, Sweden, the Netherlands, Germany, the USA, the UK, Hong Kong (formally known as the Hong Kong special Administrative Region (HKSAR), and Japan. Comparing Switzerland, the world's most competitive economy (Global Competitive Index (GCI), 2009 to 2013) against those of the two largest emerging markets - China $\left(27^{\text {th }}\right)$ and India $\left(51^{\text {st }}\right)$ (SA's BRICS partners), as well as against SA $\left(54^{\text {th }}\right)$ and Namibia $\left(74^{\text {th }}\right)$, both also emerging markets in SSA, highlights the opportunity for SA to improve its GCR position. The following table reflects these countries' scores, using the 12 mentioned pillars, taking into account the phase of development in which the country is categorised.

Table 1

Comparison of Global Competitive Index Scores - Switzerland and South Africa

\begin{tabular}{|c|c|c|c|c|}
\hline $\begin{array}{l}\text { Stages } \\
\text { (SA Score / Switzerland Score / China } \\
\text { Score / India Score / Namibia Score) }\end{array}$ & $\begin{array}{c}\text { Hinges on pillars } \\
\text { (SAScore / Switzerland Score / } \\
\text { China Score / India Score / } \\
\text { Namibia Score) }\end{array}$ & \multicolumn{3}{|c|}{$\begin{array}{l}\text { Sub-index weights used to score } \\
\text { countries, per stage of } \\
\text { development. } \\
\text { (Total }=\%)\end{array}$} \\
\hline $\begin{array}{l}\text { Key to categorising countries in stages } \\
\text { Stage 1: GDP per capita (in US\$) < 2,000 } \\
\text { Transition from Stage } 1 \text { to Stage 2: GDP per capita } \\
\text { (in US\$) } 2000-3000 \\
\text { Stage 2: GDP per capita (in US\$) } 3000-9000 \\
\text { Transition from Stage } 2 \text { to Stage 3: GDP per capita } \\
\text { (in US\$) } 9000-17000 \\
\text { Stage 3: GDP per capita (in US\$) > } 17000\end{array}$ & & $\begin{array}{l}\text { Basic require- } \\
\text { ments }\end{array}$ & $\begin{array}{l}\text { Efficiency } \\
\text { enhancers }\end{array}$ & $\begin{array}{l}\text { Innovation } \\
\text { sophistica- } \\
\text { tion factors }\end{array}$ \\
\hline
\end{tabular}

* Corresponding Author E-Mail Address: sanet.haupt@up.ac.za 


\begin{tabular}{|c|c|c|c|c|c|c|c|c|c|c|c|c|c|c|}
\hline \multirow{2}{*}{\multicolumn{6}{|c|}{$\begin{array}{l}\text { Stage 1. Factor-driven - } 38 \text { countries (India falls } \\
\text { in this category) }\end{array}$}} & \multicolumn{6}{|c|}{$1=$ Institutions } & \multirow{12}{*}{$60 \%$} & \multirow{12}{*}{$35 \%$} & \multirow{12}{*}{$5 \%$} \\
\hline & & & & & & \begin{tabular}{|l|l|}
$2010-2011$ \\
\end{tabular} & 47 & 7 & 49 & 58 & 38 & & & \\
\hline \begin{tabular}{|l|l|}
$2010-2011$ \\
\end{tabular} & 79 & 2 & 30 & & & \begin{tabular}{|l|}
$2012-2013$ \\
\end{tabular} & 43 & 5 & 50 & 70 & 52 & & & \\
\hline $2012-2013$ & 84 & 2 & 31 & 85 & 82 & \multicolumn{6}{|c|}{$2=$ Infrastructure } & & & \\
\hline \multirow{8}{*}{\multicolumn{6}{|c|}{$\begin{array}{l}\text { Countries compete based on their factor } \\
\text { endowments: primarily unskilled labour and natural } \\
\text { resources. Companies compete on the basis of price } \\
\text { and sell basic products or commodities, with their } \\
\text { low productivity reflected in low wages. }\end{array}$}} & \begin{tabular}{|l|}
$2010-2011$ \\
\end{tabular} & 63 & 6 & 50 & 86 & 54 & & & \\
\hline & & & & & & $2012-2013$ & 63 & 5 & 48 & 84 & 59 & & & \\
\hline & & & & & & \multicolumn{6}{|c|}{$3=$ Macroeconomic environment } & & & \\
\hline & & & & & & \begin{tabular}{|l|}
$2010-2011$ \\
\end{tabular} & 43 & 5 & 4 & 73 & 40 & & & \\
\hline & & & & & & \begin{tabular}{|l|}
$2012-2013$ \\
\end{tabular} & & 8 & 11 & 99 & 84 & & & \\
\hline & & & & & & \multicolumn{6}{|c|}{$4=$ Health and primary education } & & & \\
\hline & & & & & & \begin{tabular}{|l|}
$2010-2011$ \\
\end{tabular} & 129 & 7 & 37 & 104 & 112 & & & \\
\hline & & & & & & \begin{tabular}{|l|}
$2012-2013$ \\
\end{tabular} & 132 & 8 & 35 & 101 & 120 & & & \\
\hline \multicolumn{15}{|c|}{$\begin{array}{c}\text { Transition } 1-2 \\
(17 \text { countries })\end{array}$} \\
\hline \multirow{2}{*}{\multicolumn{6}{|c|}{$\begin{array}{l}\text { Stage 2. Efficiency-driven - } 33 \text { countries (South } \\
\text { Africa, China, Namibia fall in this category) }\end{array}$}} & \multicolumn{6}{|c|}{$5=$ Higher education and training } & \multirow{17}{*}{$40 \%$} & \multirow{17}{*}{$50 \%$} & \multirow{17}{*}{$10 \%$} \\
\hline & & & & & & 2010-2011 & 75 & 4 & 60 & 85 & 111 & & & \\
\hline $2010-2011$ & 25 & 36 & 2 & 4 & 114 & \begin{tabular}{|l}
$2012-2013$ \\
\end{tabular} & 84 & 3 & 62 & 86 & 119 & & & \\
\hline $2012-2013$ & 25 & 39 & 2 & 3 & & \multicolumn{6}{|c|}{$6=$ Goods market efficiency } & & & \\
\hline \multirow{13}{*}{\multicolumn{6}{|c|}{$\begin{array}{l}\text { Countries must begin to develop more efficient } \\
\text { production processes and increase product quality. }\end{array}$}} & \begin{tabular}{|l|}
$2010-2011$ \\
\end{tabular} & 40 & 4 & 43 & 71 & 56 & & & \\
\hline & & & & & & \begin{tabular}{|l|}
$2012-2013$ \\
\end{tabular} & 32 & 7 & 59 & 75 & 87 & & & \\
\hline & & & & & & \multicolumn{6}{|c|}{$7=$ Labor market efficiency } & & & \\
\hline & & & & & & \begin{tabular}{|l|}
$2010-2011$ \\
\end{tabular} & 97 & 2 & 38 & 92 & 55 & & & \\
\hline & & & & & & \begin{tabular}{|l|}
$2012-2013$ \\
\end{tabular} & 113 & 1 & 41 & 82 & 74 & & & \\
\hline & & & & & & \multicolumn{6}{|c|}{$8=$ Financial market sophistication } & & & \\
\hline & & & & & & \begin{tabular}{|l|}
$2012-2013$ \\
\end{tabular} & 3 & 9 & 54 & 21 & 48 & & & \\
\hline & & & & & & \multicolumn{6}{|c|}{$9=$ Technological readiness } & & & \\
\hline & & & & & & \begin{tabular}{|l|}
$2010-2011$ \\
\end{tabular} & 76 & 7 & 78 & 86 & 88 & & & \\
\hline & & & & & & \begin{tabular}{|l}
$2012-2013$ \\
\end{tabular} & 62 & 6 & 88 & 96 & 104 & & & \\
\hline & & & & & & \multicolumn{6}{|c|}{$10=$ Market size } & & & \\
\hline & & & & & & \begin{tabular}{|c|}
$2010-2011$ \\
\end{tabular} & 25 & 36 & 2 & \begin{tabular}{|l|}
4 \\
\end{tabular} & 114 & & & \\
\hline & & & & & & \begin{tabular}{|l}
$2012-2013$ \\
\end{tabular} & 25 & 39 & 2 & 3 & & & & \\
\hline \multicolumn{15}{|c|}{$\begin{array}{l}\text { Transition } 2-3 \\
\text { (21 countries) }\end{array}$} \\
\hline \multirow{2}{*}{\multicolumn{6}{|c|}{$\begin{array}{l}\text { Stage 3. Innovation-driven (Switzerland falls in } \\
\text { this category) }\end{array}$}} & $11=$ Busin & s sop & istic & tion & & & & & \\
\hline & & & & & & \begin{tabular}{|l|}
$2010-2011$ \\
\end{tabular} & 38 & 4 & 41 & 44 & 88 & & & \\
\hline \begin{tabular}{|l|l|}
$2010-2011$ \\
\end{tabular} & 43 & 2 & 31 & 42 & 92 & 2012-2013 & 38 & 2 & 45 & 40 & 101 & & & \\
\hline 2012-2013 & 42 & 1 & 34 & 43 & 35 & $12=$ Innov & & & & & & & & \\
\hline & & & & & & $2010-2011$ & 44 & 2 & 26 & 39 & 96 & & & \\
\hline Countries & $e_{d t}$ & $e a b$ & le to s & stain & higher wages and & \begin{tabular}{|l|}
$2012-2013$ \\
\end{tabular} & 42 & 1 & 33 & 41 & 101 & $20 \%$ & $50 \%$ & $30 \%$ \\
\hline $\begin{array}{l}\text { the associa } \\
\text { businesses } \\
\text { products. } \\
\text { through in }\end{array}$ & $\begin{array}{l}\text { d sta } \\
\text { this } \\
\text { thati }\end{array}$ & $\begin{array}{l}\text { ard } \\
\text { to c } \\
\text { ge }\end{array}$ & of livi & $\begin{array}{l}\text { g on } \\
\text { with } \\
\text { ies } n\end{array}$ & $\begin{array}{l}\text { y if their } \\
\text { new and unique } \\
\text { ust compete }\end{array}$ & & & & & & & & & \\
\hline
\end{tabular}

Source: GCR, 2009-2013

SA, being an emerging market, is also an emerging player in the powerful knowledge economy. The country has conducted its economic policy in these turbulent times (2007-2010) in commendable style, resulting in it displaying a low spread of risk. The economy has been opened up to international trade and capital flow, and has embarked on some costly pioneering social transfer programmes. The SA economy is two-tiered, with one tier competing with other countries that are highly developed, while the other tier competes with countries that largely have only fundamental infrastructure. Despite this, the economy has performed disappointingly when using its GDP as a measure. SA's GDP has, since 1994, grown by, on average, 1.2\% per annum (Rodrik, 2006), and in 2009, the GDP was 24\%, if one includes discouraged workers a $40 \%$ (Banerjee et al., 2006). In SA, the National System of Innovation (NSI) can roughly be described as a network of interacting country players and serves as inspiration for the South Africa government's broad socioeconomic mandate of fast-tracking and maintaining economic growth. It acknowledges the enormous gap between SA and other knowledge-driven economies, and, in addressing this gap, the focus is on long-term aims. This includes challenging SA's failure to commercialise the outcome of scientific research, as well as its failure to produce competent knowledge workers (qualitatively and quantitatively) in encouraging an internally competitive economy. The South African Ten-Year Innovation Plan tries to actively promote the realisation of the nation's national objectives, in alignment with the millennium goals (DTI,2008). 
SA will achieve the growth-related mandate of the government if it continues to alter the ratio of national income as a result of knowledge-based businesses, the proportion of people engaged in knowledge-based professions, as well as the percentage of organisations innovating and utilising technology. Human capital advancement, together with knowledge infrastructure, guides the progression to an economy based on knowledge. In such an economy, knowledge production and utilisation (R\&D) is vital, on condition that the discourse on the "innovation chasm" between research findings and socioeconomics is addressed.

SSA's contribution to global research output increased from $0.44 \%$ in 2003 to $0.72 \%$ in 2012, signifying reversal of the trend reported in 2007, that Africa's contribution to worldwide research was declining. However, SSA still accounts for less than 1 percent of the world's research output, still less than its share of global population at 12 percent (A decade of development in Sub-Saharan African. Science, technology, engineering and mathematics research, 2014). Two-thirds of South African periodicals are linked to life sciences, while the rest are relatively evenly spread amongst the field of science, incorporating chemistry, mathematics, and physics (Urama et al.,2010).

\subsection{Human resource on a strategic level}

Randolph (2006) posits that open collaborative business processes are taking root in the global economy, and that service innovation is emerging as an increasingly important pillar of economic growth and value. The author further argues that changing patterns of global economic activity are challenging existing policies and business strategies, which requires a globally competitive workforce. Makgoba (2010) added that such a development strategy needs to be supported by appropriate human resource policies and practices, to harness the talents of people and to build a pool of sustainable competence that can lead to greater productivity and resilience, as well as the achievement of national goals.

Both government and Universities have implemented policies to foster academic production, diffusion, and commercialisation. Universities as drivers of economic growth in the learning society are increasingly included in public policies that aim to foster innovation in the face of mounting societal demands and financial strain due to shrinking public budgets. The management of knowledge production at universities has been strengthened in order to monitor, evaluate and enhance knowledge production while accounting for spending efficiency and performance- typical features of the 'evaluation state' (Neave, 1998). The logic of knowledge commercialisation, fostered by government and University administrators via research commercialisation policies, has become institutionalised through the establishment of technology transfer offices, hiring intellectual property (IP) officers, implementing internal procedures regarding IP rights and licensing and creating ecosystems for venture capitalists (Geiger et al., 2008).

HEIs and government both participate in research and development, but with different focus areas. The common denominator that influences these three areas is human resource capital. Universities were traditionally tasked with education and research, but a new task has been added, that of knowledge transfer (community outreach), which includes generating, sharing and applying knowledge, for the prosperity and well-being of the people. Universities are confronted with original challenges and opportunities in the knowledge society, including developing into an affiliate and acting within dynamic innovation networks. A systemic view of the different environment-higher education, government and industry-highlights the intricate dynamics, as described in the triple Helix Model.

The relationship between University, industry and government (Triple Helix Model) is a complex dynamic. Industry (working towards wealth creation), academic (working towards novelty production), and government (tasked with public control) interact. This interaction results in tenuous equilibria between differentiation and integration amongst the different 
functions, according to Leydesdorff and Meyer (2006). HE is afforded the opportunity and freedom to deliberate the unthinkable. On the other hand, in the community and in business, time is of the essence and therefore, people need to confirm the possible and reject the improbable. To enable sustainable success, both sides need to function in a trans-disciplinary manner, co-creating innovative and profitable technologies and products, as well processes that empower and operate in composite ecosystems.

\subsection{Universities' responsibility for human resource development}

Globalisation has raised the prominence of higher education in a world that prioritises knowledge and innovation. HE is not only required to supply the needed quantity and quality of graduates, but also plays an important part in national innovation and development. The Southern African Regional Universities Association (SARUA) did a study titled Traditional Higher Education in Southern Africa (SARUA, 2008) which states that any investment in HE can be likened to an investment in national development. HE is thus accepted as the arena where skilled individuals cultivate competitiveness.

Universities need to participate in two types of innovation processes (Cosh, Hughes \& Lester 2004): those that are goal-oriented, with known targets and open-ended processes searching for novel strategies, markets, challenges and goals. They also need to help others to innovate. This influences the organisation of teaching and research (based on partnership and dynamic networking). Universities need to extend their innovative interaction and to influence other innovation ecosystems, leading to: innovations and innovating research; modelling innovation processes; participating in networks of innovation; changed responsibility in the innovation ecosystem; and improved innovative climate in institutions of HE. The outside world is being brought into academia and Universities need to combine research and education in their knowledge transfer activities (Laine et al., 2008). Lecturers and students are indispensable participants in the co-creation of innovations. Focusing on knowledge for innovation, developed and enhanced through human capital development, as an important factor that contributes to innovation as an economic driver, brings the role of Universities to the fore. Universities vital for the socio-economic development of a country, and can therefore not exist in isolation. They are constantly challenged by developmental concerns, social commitment and alliances and this leads to a robust HE sectors, as it Increases competition amongst such institutions.

\section{Method}

\subsection{Problem statement}

The focal point of this study was to investigate and interpret innovation adoption by academics in a HE context, and identify critical enablers and barriers influencing the process of adoption. The identified enablers of such innovative change process need to be managed so that innovation adoption is aligned with the expectation of stakeholders and the needs and values of students. The study aimed to isolate and describe the combination of factors, in the academic environment and within the academics themselves, that ignites the will to adopt innovation in spite of inhibiting and conflicting demands.

The research explored the concept of innovation adoption, crucial to change and individual variables, or combinations of contextual, organisation and personal variables influencing innovation adoption in the key functions of the institution. The empirical data from participants that emerged from systematic comparative analysis enabled a fuller a better understanding of the complexity of innovation adoption by academics. This qualitative approach (paradigm), also known as exploratory research, inductive or formative, used a case study method appropriate when looking for how and why a phenomenon happens. 


\subsection{Participants in the study}

Every second year, UP acknowledges exceptional contributions to education innovation by academics through the innovation awards. In order to generate a sample to address the research questions, nominees for the Innovation Awards were selected, as they could provide in-depth information; and the researcher could learn the most from these cases. The researcher studied a random sample of subjects who had been nominated as "innovation adopters" through this process. The sample was made up of academics from diverse faculties who were willing to participate and had the time to share their experiences. The selection of academics individual of all ages and from all levels, including new staff with a long tenure with the University. Several years of these innovation nomination cycles were incorporated into the study, leading to a longitudinal time zone (three cycles). The nominations was based on a reflective practice informed by research. Previous winners are eligible for nomination for novel contributions in following cycles. The nominations then need to be directed to the Director: Department for Education Innovation, where nominations are put through a stringent double-blind peer evaluation process, overseen by an external evaluator.

A double-blind peer-review process is applied to evaluate and rank all submissions, following a double-blind assessment methodology. Data were collected through questionnaires and individual interviews with each nominee, according to a predetermined list of questions to steers the interview. The data collected during the initial sessions directed the resource sampling of video-taped presentations done by the nominees as part of the evaluation process for the Innovation Awards. This was complemented by analysis of the written submissions made by each nominee, which described and positioned their innovation nominations.

\subsection{Data capturing and analysis}

The data capturing was done using notes, supported by cognitive mapping indicating the relationship between concepts. Transcripts of interviews capturing the essence of innovation adoption were added to the field notes to ensure comprehension. Innovation adoption practices of selected nominees of the 2008, and the 2012 (the awards are given every second year) were analysed separately ex post. Qualitative data-analysis procedures were followed to build a descriptive framework that was adequately grounded in the data. In the present study, the data was categorised and unitised, to recognise relationship before reaching any conclusion. Theoretical comparison helped to control bias and to enhance objectivity, while retaining sensitivity.

\section{Discussion}

\subsection{Organisational learning and knowledge creation}

Organisational learning culture has evolved from only a competency understanding to also include the process element, while connecting learning opportunities and organisational behaviours. Organisations with a competitive advantage have the capacity to learn and respond to internal and external business environments. Knowledge creation is an organisation's unique and unmatched advantage. The competitiveness of an organisation is the results of its employee specialised knowledge, new knowledge that is generated by the organisation and the strategic actions made possible by innovation (Grant, 1996). The application of knowledge is the ability to put what one learns into practice and this increases one's competence. Human learning can be defined as acquiring new or modify existing knowledge, behaviours, skills, attitudes and values or preferences. Bloom's taxonomy of learning underpins these overlapping domains of cognitive (knowledge), affective (attitude) and psychomotor (skills) domains and the concept of developing competence, as knowledge workers, at the highest levels (Levels 5 and 6) (Bloom et al ., 1956). Advances in and new understanding of cognitive science and pedagogical and learning research are included in Bloom's revised taxonomy. These added levels of 
thinking throughout the taxonomy, and are: remembering, understanding, applying, analysing and creating (Johnson, Gaspar, Boyer, Bennett \& Armitage, 2012).

\subsection{Knowledge management}

Knowledge management capacity is critical for competitiveness (Bernard \& Tichkiewitch, 2008) and encompasses the all-inclusive knowledge acquisition and utilisation process, in an attempt to rationalise and manage the vast amounts of formal and informal knowledge that any organisation possesses (Simone, Ackerman \& Wulf, 2012). The process runs from locating or identifying and capturing knowledge within the organisation (Takeuchi \& Nonaka, 2004). Knowledge management exemplifies a collection of organisational procedures that procures knowledge, assimilates it internally and then transmit and exploit it in the organisation. These procedures all influence the organisation's absorptive capacity (Zhou, Tan \& Uhlaner, 2007). To conceptualise the relationship between knowledge management (focusing on the content) and organisational learning (focusing on the process) is to view organisational learning as the goal of knowledge management. Knowledge management assist organisation to embed knowledge into organisational processes, in order to unremittingly improve its practices and behaviours to realise its goal. In this sense, organisational learning is a way for an organisation to improve its utilisation of knowledge, leading to improve organisational performance. Utilisation happens by individual as well as collective learning leading to shared problemsolving and developing various interpretations to innovate. By embedding knowledge, it can be re-used. (King, 2009). Managing knowledge in a learning organisation has developed into an integral aspect of an organisational culture that thrives on innovation, data mining and R\&D. The practice of knowledge management is associated with managerial thinking, employee behaviour and decision-making under organisational settings. Managing the knowledge resource in an organisation allows managers to oversee how generated knowledge is utilised, shared, and retrieve (Chatterjee, 2014). It is important to remove constraints and organisational obstacles to knowledge management. Both the bureaucratic and hierarchical organisational forms and the situated and tacit character of knowledge make it difficult to extract and transfer knowledge (Chatterjee, 2014). Organisational structures should be grounded on the principles of which, facilitate the growth of knowledge, enable transfer of knowledge, and increase the flow of information.

\subsection{Innovation orientation}

Organisational innovativeness is an organisation's overall innovative capability by pioneering novel products in the market, or unlocking new markets, through the combination of strategic orientation and innovative behaviour and processes (Wang \& Ahmed, 2004). Innovation is associated with creativity and change (Drucker, 1991; Hellriegel et al., 1998; Robbins, 1996) or is deemed as something new, leading to change (West \& Farr, 1990). This gives the impression that the standard for innovativeness is multi-dimensional and grounded in products and or/ services, processes, behavioural (culture) and infrastructure characteristics. Market orientation is known as an organisational culture that favours behaviours dictating how employees should think and act as it relates to the realisation of the marketing concept (Day, 1990; Jaworski \& Kohli, 1990). Innovation includes: Conception, suggestion of an idea, adoption and implementation of the innovation. Systemic learning capabilities may be a critical success factor for organisations with important knowledge acquisition and implementation (Calisir et al., 2013). Learning orientation is the presence of values that affect the degree to which an organisation questions its theories in use, its mental models and its dominant logic (Li \& Lin, 2008) and comprises aspects, such as managerial commitments and risk taking combined with experimentation, open-mindedness and shared vision, dialogue and participative decision making combined with inter-organisational knowledge sharing, creative 
thinking and team improvement, and interaction with the external environment, (Calisir et al., 2013). The process of innovation transforms valuable ideas into novel shapes of economic value for all stakeholders. This process of knowledge-creation by way of a transformation process alters existing information into novel knowledge as a form of social capital. This transformation process (implicit knowledge converted into knowledge) is an organisational learning process to preserve continuity based on innovation grounded in creativity (MerxChermin et al., 2005) Such modification between specific and shared transformation is vital for organisational innovation.

\subsection{Concept of creativity}

Creativity, which drives innovation, is not necessarily a gift but a creative thinking process or else the consequence of a creative thought (Eysenck, 1994); it can be learned and often requires an altered working environment (Hernandez, 2010). Engagement in a disciplined process is required to create a new level on which original and novel ideas could be generated, through the simultaneous activation of diverse, often unrelated, ideas or categories (Rothenberg, 1996). Product-oriented creativity is the result of the interplay between divergent thinking process (Kharkhurin et al., 2008), satisfying the requirements of novelty appropriateness, and usefulness (Lubart \& Sternberg, 1995). Inventiveness, adaptability, and productivity require creativity to occur, and are important for functioning and prospering in an innovation economy. People, especially in the knowledge economy, need to team up and blend in creative and bold ways their knowledge, skills, and capabilities, to identify and solve complex problems (Norman, 2006). Creativity generates new ideas while innovation realise, implement, and test creative ideas (Fagerberg et al., 2005).

\subsection{Classification of innovation}

Innovation is the mechanism for change. Defying change is dangerous. Organisations are not able to shield themselves from change, notwithstanding their superiority or the limitlessness of their current resources (Koornhof, 2001). Change, effects uncertainty and risk, and produces opportunity. As Buckler (1997) implies, innovation "is an environment, a culturealmost spiritual force-that exists in a company" and leads to the creation of value. It extends across all the actions needed to deliver customer value coupled with an acceptable return for the organisation.

\subsection{Sources of innovation}

Innovation is generally unstructured and cannot easily be portrayed linearly. Innovation has transformed from a linear model to a non-linear and more complex relationship-based model. Innovation is no longer a process of fixed linear sequence of phases but is the result of numerous actions of many players (Mbananga, 2007). Kenny and colleagues found in an investigation into the impact of organisational culture factors on innovation levels, that the top internal and external sources of innovative ideas were identified as management, the managing director and customers (Kenny et al.,2007). The top nine important sources of innovation, ranked from highest to lowest importance, were identified as: Customers; customers' customers; networking; Universities and colleges; technology transfer; suppliers (strategic fore sighting); internet; trade associations; and internal company resources. Zahra \& Covin (1994) note that corporate undertakings to acquire innovation can be either through imitation, acquisition or incubation. The difference between the sources of innovation is of the essence, as it decides the time and attention allocation, in addition to the rate and adoption speed. Once a selected source is merged with an appropriate structural arrangement, the efficacy of the selected source is enhanced (Damanpour \& Gopalakrishnan, 1998). 


\subsection{Barriers to innovation}

A study from the Austrian Institute of Economic Research by HólzI and Janger (2012) confirmed the relevance of differentiating barriers between innovation-hampering (innovation firms) and deterring (non-innovative firms) (D'Este et al., 2012). Loewe \& Dominiquini (2006) reported that an 'innovation diagnostic' can review opportunities in the pipeline and marketplace result and compare them with practices of leading innovators, rather than blindly copying best practices.

\subsection{Innovation process}

Innovation is the decisive organisation and focused use of organisational abilities and knowledge (Pitt \& Clarke, 1999). The innovation process has different phases and the greatest hurdles of the process are in the spaces between the different phases, affected by the people involved and their attitudes. The first phase is to generate or create timely ideas by capturing, aggregating, and acknowledging. Ideas arise as "wow" moments or as a consequence of the determined hunt for opportunities (Drucker, 1985). Preserving innovative ideas together with related information in an accessible central and common location preventing reinvention and allows reintroduction of ideas because of changed circumstances (Dinsdale et al.2002; Cooper et al. 2002). Inherent challenges to the process of innovation are addressed in the techniques and approaches that surround each phase. Adams (2005) motivates that finding points of common interest in the institution will unite employees and mobilise their support to innovation. The intersection between disciplines or cultures creates the best chance to innovate because so many unusual ideas are generated by diverse employees. Exposure to more than one culture shatters barriers because an intricate association exists between domain specific expertise and the ability to think outside that domain's established paradigm. An inhibitor of creativity is how our minds create order in a chaotic world by clustering associations around a concept. If these associative barriers are low, they make unusual connections leading to successful creativity and the intersection of ideas ultimately leads to innovation. (Adams 2005).

\subsection{Adoption of innovation}

Thompson and Purdy (2009) found that successful innovation adoption is positively related to agreement about innovation congruence. Innovation adoption increase the significance of some values and beliefs over others, through changes in resources, practices, and relationships (Thompson \& Purdy, 2009) and, once adopted, the innovation becomes part of the organisation's practices and culture. Innovation represents 'a collective achievement of pushing and riding ideas into good currency (Van de Ven, 1986) and this leads to the conclusion that faculty composition is a critical contextual variable affecting the innovation process (Thompson \& Purdy, 2009) influenced by relative value of hard and soft skills stemming from professional ideologies and norms

\subsection{Factors influencing innovation adoption}

Economic globalisation selectively creates new jobs, and changes relationships between education, jobs, and rewards. The world has entered a global knowledge where barriers are disintegrating in favour of international trade and investment. This global knowledge economy is characterised by knowledge-intensive industries, driven by the application of new technologies, thereby increasing labour market flexibility. Wong \& Chin (2007) report that to gratify customer expectations, organisations need to provide products and services perceived to be valuable measuring them against performance indicators of organisational innovation. The authors continue by stating that the notion of globalisation has its own domain and an international perspective from which change can be comprehended. 
Organisations are pressure to function in multiple time regions, prospecting for new opportunities while also analysing current situations. Organisations are also expected to be extensive in their reach, small in size, operative and efficient (Gavetti \& Levinthal, 2000; Miles et al., 1978). High-ranking employees need to be progressive and backward-thinking, while they maintain equilibrium between exploratory and exploitative actions. Exploiting promotes inactivity, as well as conservatism, and crushes exploration (Benner \& Tushman, 2002). Exploration effects productivity, but too much exploration can prevent learning by doing or achieving economies of scale (He \& Wong, 2004).In order for organisations to successfully compete, they need to simultaneously be flexible and focused, while also learning and unlearning (Bunderson \& Sutcliffe, 2002). Short-term efficiency in addition to long-term innovation holds the key to sustained performance. Novel "organisational practices" are key to the mentioned contradictions, as they hold the potential to produce innovative advanced in functioning (Laursen \&Foss, 2003) efficiency (Datta et al., 2005) and profitability (Mendelson, 2000). The full realisation of potential benefit is dependent on organisations introducing a set of organisational practices that mutually reinforcing.

\subsection{Culture and climate for innovation}

Innovation is a means to radically influence an organisation's efficiency and effectiveness. The culture of an organisation needs to support an innovative focus, to enhance the organisational brand and replica or improve on the work of others. Members of a given culture share socially constructed meaning, and deal with issues relating to the ecosystem (Hofstede, 1980). Kharkhurin \& Motalleebi (2008) report that diverse cultures contribute different concepts of creativity, and use dissimilar psychological processes when they engage in creative endeavours. The environment can either positively or negatively influence people's creativity. Creativity as a concept is decided and moulded by sociocultural values and norms, which, may have an influence on the way in which creative potential is captured and incarnated.

\subsection{Funding of higher education institutions}

An essential requirement, articulated in constitutional terms, of an institution's autonomy and academic freedom is the search for wisdom and the perpetuation of the standards on which an educated civilisation hinges (Middlehurst, 2004). The intention is to ensure orderly procedures, broad consultation and weighted judgements, as well as a match with the external environment (Middlehurst, 2004). The liberal ideal accentuates the innate worth of learning, separate from learning for occupational reasons. The new economic ideology sees education as an economic resource in support of industrial development (Middlehurst, 2004). This allows government, through funding and quality assurance, to exercise power, as Universities are placed at the centre of cultural, social, and economic actions, linked to the knowledge-status pyramid in society.

\subsection{Public HE context (SA)}

From a global perspective, considering the knowledge economy, HE in SA plays a pivotal role in national development. 'Prima facie, indicators such as shortages of high-level skills and the concurrent of graduate unemployment suggest that there is a significant mismatch between the output of the sector and the needs of the economy' (CHE, 2007) Recent data (A proposal for undergraduate curriculum reform in South Africa: The case for a flexible curriculum structure from the CHE, 2013) highlight alarmingly low levels of performance in this sector. Transformation is rooted in change that is steered by knowledge, leading to improved effectiveness of teaching and learning in HE. The UP strategy speaks to challenges and opportunities for academic on a global platform. These challenges question the prisms through 
which academics approach their work, and hold the possibility of innovation. The challenge is to be relevant in the rather complex South African society. In moderation, innovation is, to some, a mind-set and, in that sense, some people will always look for something interesting, new, or original, and test ways to see if these are more effective or have more impact. These concepts need to be explored more in the institution, and nurtured by investing in UP talent. Some faculties/department are responsive to the impact of globalisation on the academic disciplines and the teaching thereof. Innovation is a very important component of their strategic plan. Academics are also responsible for keeping up with global trends by attending international conferences and interacting with global role players.

\subsection{University of Pretoria}

In the ongoing discussions regarding the reform of $\mathrm{HE}$ in $\mathrm{SA}$, it is evident that the dominant issue governing proposals to transform Universities is social transformation. The recent debate regarding whether such political, social, and economic roles should be assigned to Universities in SA, has been taken up by Higgs (2002) and Mthembu (2004). A case study of UP, a researchintensive HEI, institution (UP, 2006), is the empirical source of data from which claims are made in this research. UP is the largest contact residential Universities in the metropolitan area of Tshwane, and consists of nine faculties, and a business school, comprising 134 department and 19 support services departments. The University functions from six campuses and various other sites of operation. The University aims to positively contribute, both locally and internationally, to the knowledge production in the country. The mission of UP in the institutions' strategic plan of 2007 to 2011 was expressed in its three principal purposes of research, teaching and learning and service learning, relates to being locally relevant and internationally competitive and (UP, 2006).

The extent to which innovation is integrated into the organisation and how it changes the execution and outcome of processes determine the success of innovation adoption (Damanpour \& Gopalakrishnan, 1997). The challenge that faces UP as an internationally renowned South African University is to agree on a common understanding of the term the innovation generation. UP needs to ensure that pedagogical innovation, as derived from a common understanding, is successfully adopted in the organisation as part of its academic excellence, quality, and innovation strategy.

\section{Results and Conclusion}

\subsection{Data analysis of factors affecting innovation adoption}

This research has identified factors that encourage or discourage the adoption of innovation in the working environment of academic at UP. The results of this qualitative case study relied on an interpretive constructivist epistemology. The HE and institutional context in which these academics are active was highlighted, as it significantly impacts their innovation adoption ability. The analysis was completed by organising data according to specific topics or themes across respondents' feedback. Practices were identified based on the existing theory, and were grouped under these themes. Emerging themes were captured whilst analysing the data, until data saturation had occurred. Coding, summarising, and further analyses were conducted: specific coding was used to identify themes and subthemes. Key findings were listed while categorising and sorting data. Findings and results were based on relevant facts, avoiding generalisation. Credibility was ensured by keeping record of data for cross-referencing (Leedy \& Omrod, 2005).

The changing environment in which $\mathrm{HE}$ is situated acts as a catalyst for innovation, as academics need to think differently and introduce changes to cope with these challenges. Pressure is put on academics in UP to cope with the combination of the range and quality of the institution's programmes and the institution's size, while positioning the institution as a 
leading producer of quality graduate for the national and international marketplace. This pressure frames what academic perceive innovation to be in relation to their teaching.

\subsection{Recommendations}

The risk to SA is a diminishing pool of the talent that is required for a competitive advantage. As a consequence of the economic crisis, it was pivotal for SA to maintain and increase employment opportunities. An essential part of all sector revival agendas is focused on developing skills and promoting high-level competencies. A permutation of actions on public employment, private sector initiatives, and training could be complementary to countercyclical measure to escape a recession and possible job losses. In a complex, interrelated environment in the context of a rapidly changing economy and employment market, the commitment to adopt innovation may require specific, tangible resources that Universities may not be able to supply, such as substantial funding. Leaders need to understand that there are fundamental challenges in achieving innovation adoption and that there are factors outside of the academic's sphere that impact the change process in HE. These includes leadership, constructive alignment between stakeholder's expectations and behaviours, business processes and available resources.

There is a sound rationale for connecting. HE to enterprise and ultimately employability, but there can be fundamental challenges in achieving this desirable and necessary shift, such as academic management, culture, employers' perceptions and experiences of HEIs, as well as student expectations and behaviours. Some effective and innovative practices are being deployed by Universities in novel ways to overcome these challenges. These practices, through and beyond the curriculum progress, suggest that by connecting together interactions between University students, staff, and employers these challenges can be overcome. This can be conceptualised on two levels: through institutional connectivity and through integration of the individual learning experience, demonstrating innovative and enterprising learning-centred approaches that are in accord with government policy on HE. It is difficult to rely on a single strategy for the enhancement of employability skills; a mix of learning and development approaches would be beneficial.

The research aimed to contribute to the literature on factors affecting innovation adoption in a HE institution by providing an inventory of possible factors. In developing the inventory, the researcher focused on academic's innovation adoption behaviour, drawing on a literature review, documents and interview.

\section{Acknowledgement}

This paper is an output of the PHD study 'FACTORS INFLUENCING INNOVATION ADOPTION IN A HIGHER EDUCATION INSTITUTION' in the Faculty of Economic Management, University of Pretoria.

\section{References}

A decade of development in Sub-Saharan African. Science, technology, engineering \& mathematics research. (2014). Research Trends, 39.

Adams, K. (2005) Sources of innovation and creativity. National centre on Education and the Economy (NCEE). July, 2005.

Banerjee, A., Galiani, S., Levinsohn, J. \& Woolard, I. 2006. Why has unemployment risen in the new South Africa? CID working paper, 134:1-64 
Benner, M J. \& Tushman, M. (2002). Process Management and Technological Innovation: A Longitudinal study of the Photography and paint Industries. Administrative Science Quarterly, 47(2000): 676-706

Bernard, A. \& Tichkiewitch, S. (2008). Book: Methods and Tools for Effective Knowledge Life-Cycle-Management.

Bloom, B. S. \& Krathwohl, D R. (1956). Book: Taxonomy of Educational Objectives: The Classification of educational Goals. Handbook 1: Cognitive Domain.

Buckler, S.A (1997). The spiritual nature of innovation. Research-Technology Management: 43-47.

Bunderson, J. S. \& Sutcliffe, K. M. (2002). Comparing alternative conceptualisations of functional diversity in management teams: process and performance effects. Academy of Management Journal, 45(5):875-893

Calisir, F \& Gumussoy, C, A. \& Guzelsoy, E (2013). Impacts of learning orientation on product innovation performance

Chatterjee, S. (2014). Managing Constraints and Removing Obstacles to Knowledge Management. http://mpra.ub.uni-muenchen.de/57789/

CHE. (2007). A Case for Improving Teaching and Learning in South African Higher Education, HE Monitor No. 6

CHE. (2013). a proposal for undergraduate curriculum reform in South Africa: The case for a flexible curriculum structure. Report of the Task Team on Undergraduate Curriculum Structure Council on Higher Education.

Cooper, R. G., Edgett, S. J. \& Kleinschmidt, E.J (2002). Optimising the stage-gate process: what best practice companies do-I. Research-Technology Management, 45(5): 21-27

Cosh, A., Hughes, A., \& Lester, R (2004). International Innovation Benchmarking and the Business-University Linkage. Presentation at the Cambridge-MTI Institute National Competitiveness Summit. Retrieved January 72008.

D'Este, P. Iammarino, S., Savona, M. \& von Tunzelmann, N. (2012). What hampers innovation? Revealed barriers versus deterring barriers. Research policy 41(2012): 482-488

Damanpour, F. \& Gopalakrishnan, S. (1998). Theories of organisational structure and innovation adoption: the role of environmental change. Journal of Engineering Technology Management, 15:1-24

Datta, D.K., Guthrie,J.P \& Wright, P. M. (2005). Human Resource Management and Labour Productivity: Does industry matter? Academy of management Journal, 48(1): 135:145

Day, W.B (1990). Distributed Multi-agent planning. Rome Air Development Centre, Final Technical Report (AD-A233522)

Department of Science and Technology (DST) (2008). South African Ten-Year Innovation Plan.

Dinsdale, G., Chhabra, S \& Rath-Wilson, J. (2002). A Toolkit for E-Government: Issues, impacts and insights. For the IDB Regional Policy Dialogue.

Drucker, P. (1985). Entrepreneurship and innovation: Practice and principles. New York NY: hamper Business

Drucker, P. (1991). Drucker in Harvard Business Review. Harvard Business Review 
Eysenck, H.J. (1994). Book: The measurement of creativity: 199-242. The MIT Press.

Fagerberg, J. \& Srholec, M. (2005). CATCHING UP: WHAT ARE THE CRITCALFACTORS FOR SUCCESS? Background paper for the UNIDO world Industrial Development Reportpreliminary version.

Gavetti, G. \& Levinthal, D. (2000). Looking forward and looking backward: Cognitive and Experiential Search. Administrative Science Quarterly,45(1):113-137

Geiger, R.L \& SA, C. M. (2008). Tapping the riches of science: Universities and the promise of economic growth, Harvard University Press

Grant, R.M (1996). Prospering in Dynamically-Competitive Environments: Organizational Capability as Knowledge Integration. Organization Science, 7(4): 375-387

He ZL, Wong PK. (2004). Exploration vs. exploitation: An empirical test of the ambidexterity hypothesis. Organization Science, 15:481-494.

Hellriegel, D \& Slowcum, J.W. \& Woodman, R. W (1998). Book: Organisational behaviour. South-western College Publications

Hernandez, G. (2010). Mech-Tech builds recyclable 100\% electric vehicle. Caribbean business, March 4.

Higgs, P. (2002). Nation building and the role of the university: a critical reflection. SAJHE/SATHO, 16(2).

Higgs, P. (2004). Education for responsibility: Possibilities of a Derridian text for University education. Perspectives in Education, 22(1).

Hofstede, G (1980). Cultures consequences: International differences in work-related values. Beverley Hills, CA:Sage

Holzl, W. \& Janger, J. WIFO Oserreichischies Institut Fur Wirtschaftforschung. Innovation Barriers across Firms and Countries. Working paper.

Jaworski, B.J. \&Kohli, A. K. (1993).Market orientation: Antecedents and consequences. Journal of Marketing, 57 (July 1993):53-70

Johnson, G., Gaspar, A., Boyer, N., Bennett, C. \& Armitage, W. (2012). Applying the revised Bloom's Taxonomy of the cognitive domain to Linux system administration assessments. Consortium for Computing Science Colleges.

Kenny, B. \& Reedy, E. (2007). The impact of organisational Culture factors on Innovation Levels in SMEs: An Empirical Investigation. Department of Business, Tipperary Institute

Kerlavaj et al., 2007

Kharkhurin, A.V. \& Motalleebi, S.N.S (2008). The impact of culture on the creative potential of American, Russian and Iranian College students. Creativity Research Journal 20(4): 404411.

King,W. R (2009). Boon to Knowledge management. Information systems, management, 26(1)

Koornhof, C (2001). Developing a framework for flexibility within organisations. South African Journal of Business management, 32(4): 21-29

Laine, K.,van der Sijde, P., Lähdeniemi, M. \& Tarkkanen, J. (2008). Higher Education Institutions and Innovation in the knowledge society. The Rectors' conference of Finnish Universities of applied Science ARENE 
Laursen, K. \& Foss, N. J. (2003). N, HRM practises, complementarities and the impact of innovation performance. Cambridge Journal of Economics, 27(2): 243-263

Leedy, P.D., \& Ormod, J.E. (2005). Practical Research Planning and Design (5 ${ }^{\text {th }}$ Ed.). New Jersey: Pearson Merrill Prentice Hall

Leydesdorff, L \& Meyer, M (2006). Triple Helix indicators of knowledge-based innovation systems Introduction to the special issue. Science and Research Policy, 25(3): 195-203.

Li,C.R.,Lin, C.J., \& Chu, C.P. (2008). The nature of market orientation and the ambidexterity of innovations. Management Decision, 46(7), 1002-1026.

Loewe, P. \& Dominiquini, J. (2006). Overcoming the barriers to effective innovation. Strategy and Leadership, 34(1): 24-31,

Lubart, T. I. \& Sternberg, R. J. (1995). Book: The creative cognition process. Chapter 12- An investment Approach to Creativity: Theory and data: 271-298. MIT Press

Makgoba, M. (2010). Living the true meaning of the National System of Innovation. Focus, $59,67-73$.

Mbananga, N (2007). Placing knowledge management within SA DST Plan (2008 - 2018): Innovation towards a Knowledge-based Economy. Prepared for the ICICKM Conference Stellenbosch University Western Cape South Africa

Mendelsson, H. (2000). Organisational architecture and success in the information technology industry. Management Science, 46(4): 513-529

Merx-Chermin, M \& Nijhof, W. J. (2005). Factors influencing knowledge creation and innovation in an organisation. Journal of European Industrial Training, 29 (2):135-147

Middlehurst, R. (20040 Higher Education Quarterly, 0951-5224 volume 58, No. 4, pp 258-279. Challenging Internal Governance: Discussion of Leadership Roles and Management Structures in UK Universities.

Miles, R.E., Snow, C. C., Meyer, A. D. \& Coleman, H. J. (1978). Organisational strategy, structure and process. The academy of Management Review, 3(3): 546-562

Mtembu, T (2004). Creating a Niche in Internationalization for (South) African Higher Education Institutions. Journal of Studies in International Education, 8(3):282-296

Neave, G. (1988). On the cultivation of quality, efficiency and enterprise; an overview of recent trends in higher education in Western Europe, 1986-1988. European Journal of Education, 23(1/2), 7-23.

Norman Jackson (2008). Tackling the Wicked Problem of Creativity in Higher Education. Background paper for a presentation at the ARC Centre for the Creative Industries and Innovation, International Conference Brisbane June 2008. Creating Value: Between Commerce and Commons.

Pitt, M. \& Clarke, K. (1999). Competing on competence: A knowledge perspective on the management of strategic innovation. Technology Analysis \& strategic Management, 11(3): 301-316

Randolph, L. H. (2006). Leadership through partnership: A collaborative, strengths-based approach to strategic planning: 1081-1088

Robbins, S. P. \& Coulter, M. (1996). Managing innovation and change. In management $\left(5^{\text {th }}\right.$ edition) Prentice Hall 
Rodrik, D. (2006). Understanding South Africa's Economic Puzzles. Paper prepared for Harvard University Centre for international Development Project on South Africa, September 2006:1-55

Rothenberg, A. (1996). The Janusian process in Scientific Creativity Research Journal, 9(2-3)

SARUA (2008). Towards a Common Future. Higher Education in the SADC Region. Research Findings from Four SARUA Studies.

Simone, C., Ackerman, M. \& Wulf, V. (2012). Knowledge management in Practice: A special issue Computer supported cooperative work 21: 109-110

Takeuchi, H. \& Nonaka, I. (2004). Knowledge creation and Dialectics. Hitotsubashi on knowledge management-chapter 1: 1-35

Thompson, T. A \& Purdy J. M. (2009). When a good idea isn't enough: Curricular Innovation as a Political Process. Academy of Management Learning Na Education, 8(2): 188-207

UP (2006). University of Pretoria Strategic plan 2007-2011

Urama, K. C., Ozor, N., Kane, O. \& Hassan, M. (2010). Unescco Science Report 2010. SubSaharan Africa

Van de Ven, A. H. \& Poole, M.S. (2005). Alternative approaches for studying organisational change. Organisation studies 26.9: 1377-1404

Van de Ven, A. H. (1986). Central problems in the management of innovation. Management Science, 32(5)

Wang, C. L. and Ahmed, P. K. (2004). The development and validation of the organisational innovativeness construct using confirmatory factor analysis. European Journal of Innovation Management, 7(4):303-313

West, M \& Farr, J. L. (1190). Innovation at work in M.A. West \& J. L Farr (eds), Innovation and creativity at work: psychological and organisational strategies. John Wiley and Sons, Ltd: 3-13

Wong, S. \& Chin, K (2007). Organisational innovation management. Industrial Management and Data systems, 107 (9): 1290-1315

Zahra, S. A. \& Convin, J. G. (1994). The financial implications of fit between competitive strategy and innovation types and sources. The Journal of High Technology Management Research, 5(2): 183-211

Zhou, H., Tan, S. Y. G. L. \& Uhlaner, L. (2007). Knowledge management and innovation: An Emperical study of Dutch SME's. Scientific, Analysis of entrepreneurship and SME's. Netherlands Ministry of Economic Affairs. 